\title{
Miniaturized Dipole Antenna Development for Low Frequency Ground Penetrating Radar (GPR) System
}

\author{
Omar Faruq Howlader and Tariq Pervez Sattar \\ Mechatronics, Robotics and Non-Destructive Testing Research (MrNDT) London South Bank \\ University.
}

\section{Abstract}

A miniaturized symmetrical dipole antenna with extra radiating arms is proposed for low frequency operation $(100 \mathrm{MHz})$ in ground penetrating radar applications to achieve high depth penetration at low resolution. The dipole antenna design is of total dimension $66.5 \mathrm{~cm} \times 22 \mathrm{~cm}$. A parametric study of antenna performance is performed via simulation with Agilent Advanced Digital System software which indicates an optimum length of $15 \mathrm{~cm}$ for the extra arm with a gap of $5 \mathrm{~cm}$ between the dipole arm and extra arm. The results are validated experimentally in room conditions with a prototype antenna fabricated on $1.6 \mathrm{~mm}$ thick FRA substrate, copper layer thickness of $17 \mu \mathrm{m}$. The antenna operating at a centre frequency of $104 \mathrm{MHz}$ and bandwidth of $8 \mathrm{MHz}$ for VSWR $\leq 2$ achieves a $55 \%$ reduction in length compared to a conventional dipole operating at $100 \mathrm{MHz}$ while delivering typical dipole radiation pattern with directivity gain of $2.06 \mathrm{dBi}$.

\section{Introduction}

- A miniaturized symmetrical dipole antenna with extra radiating arms is proposed for low frequency operation (100 MHz).

- Physical size and gain of antennas are determined by the operating frequency.

- Small antennas offer compact system dimension.

- Small antennas have a low gain at lower frequencies and larger antennas are required to operate at lower frequencies.

\section{Background}

- Application of GPR in low frequency region.

- GPR frequency ranges from $10 \mathrm{MHz}-2 \mathrm{GHz}$ depending on depth penetration and resolution.

- Higher frequency offers low depth penetration and high signal attenuation problem [1].

- Low frequency delivers high depth penetration at low resolution.

\begin{tabular}{|c|c|c|c|c|}
\hline $\begin{array}{c}\text { Frequency, } \\
\mathbf{M H z}\end{array}$ & 2000 & 900 & 500 & 300 \\
\hline Resolution, $\mathrm{m}$ & $0.04-0.08$ & 0.2 & 0.5 & 1.0 \\
\hline Depth, $\mathrm{m}$ & $1.5-2$ & $3-5$ & $7-10$ & $7-10$ \\
\hline Blind Zone, $\mathrm{m}$ & 0.06 & $0.1-0.2$ & $0.25-0.5$ & $0.5-1.0$ \\
\hline
\end{tabular}

Table 1: Performance of GPR with different frequencies [2]. 

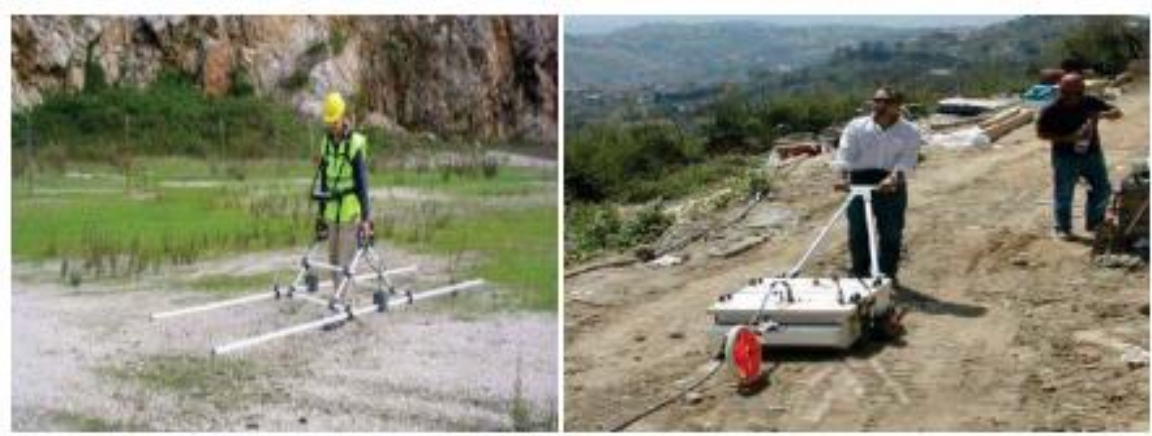

Figure 1: GPR scanning with $100 \mathrm{MHz}$ unshielded and shielded dipole antenna.

\section{Dipole Antenna Miniaturization}

- $31 \%$ length reduction is recorded for $500 \mathrm{MHz}$ bow-tie antenna in [3].

- $26 \%$ reduction is recorded for $700 \mathrm{MHz}$ folded dipole antenna in [4].

- Most of the miniaturization techniques found in literature are for high frequency antennas.

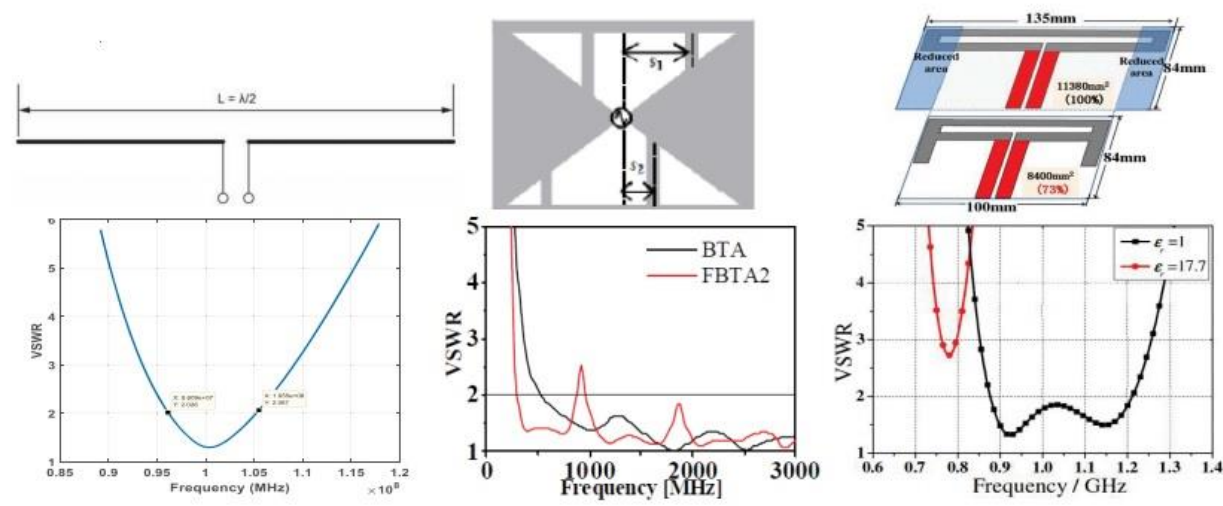

Figure 2: VSWR characteristics of conventional dipole antenna, antenna proposed in [3] and [4].

\section{Proposed Antenna Design}

- A dipole antenna with extra radiating arms is proposed.

- Total antenna dimension is $66.5 \mathrm{~cm} \times 22 \mathrm{~cm}$.

- Effect of different length of extra arms, I and the gap between the dipole arm and extra arm, $\mathrm{g}$ are studied in parametric study.

- Agilent Advanced Digital System (ADS) software suite is used for simulations. 


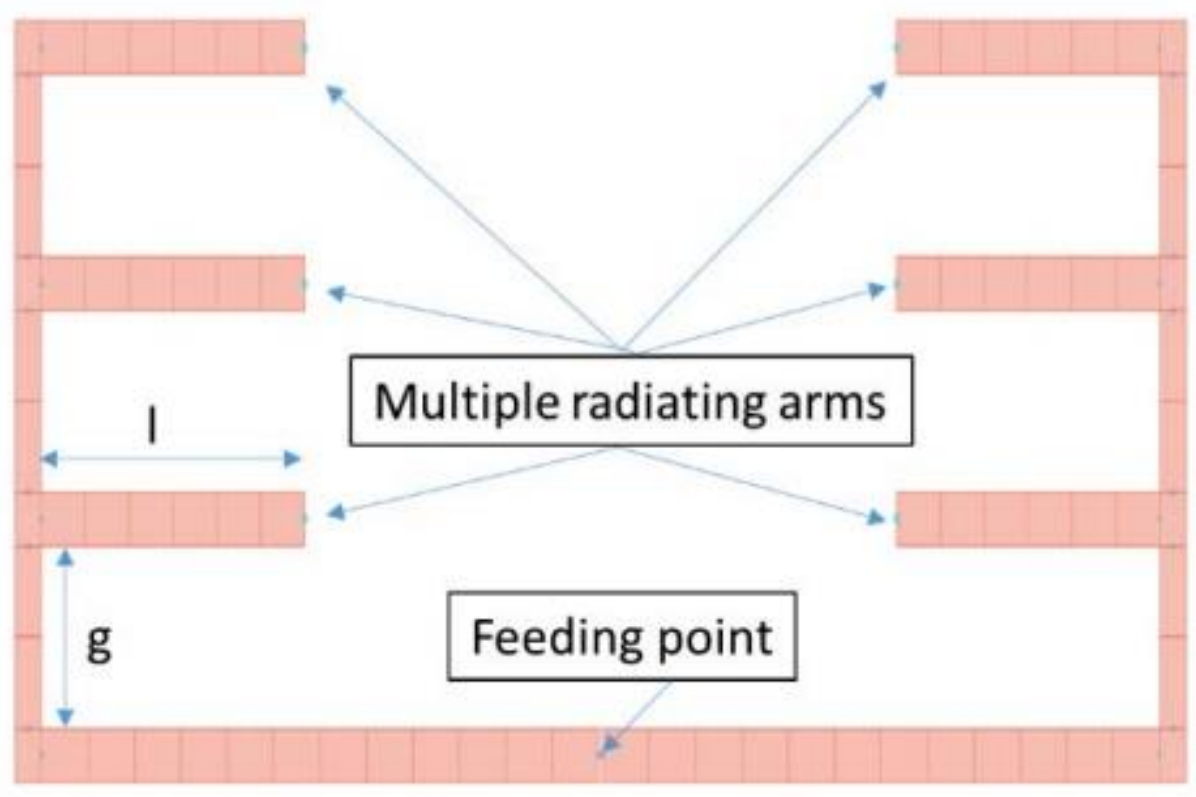

Figure 3: Proposed miniaturized $100 \mathrm{MHz}$ dipole antenna.

\section{Parametric Study of Antenna Performance}
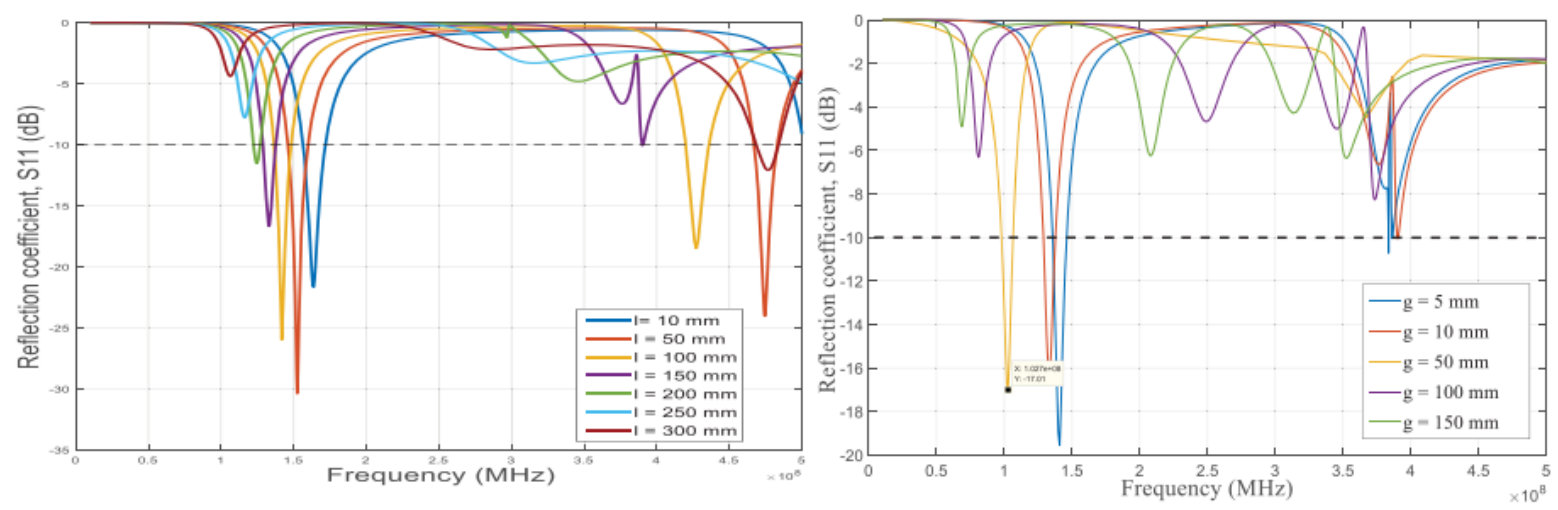

Figure 4: Reflection coefficient, S11 values for different I and $g$.

Optimum values: At $I=15 \mathrm{~cm}$ and $g=5 \mathrm{~cm}$, centre frequency $=102 \mathrm{MHz}$

\section{Antenna Performance}

Figure 5: Current density distribution on the proposed antenna compared to a conventional dipole. 


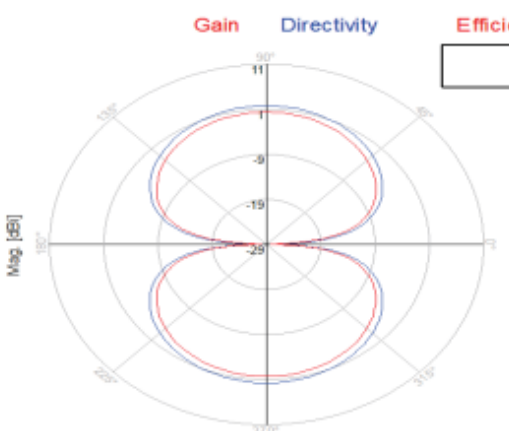

Phi (0.000 to 360.000$)$

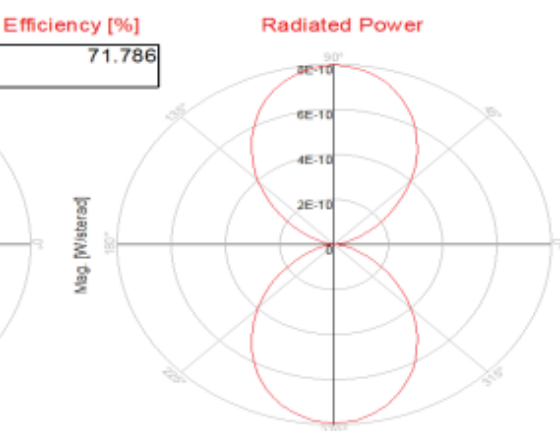

Phi $(0.000$ to 360000$)$

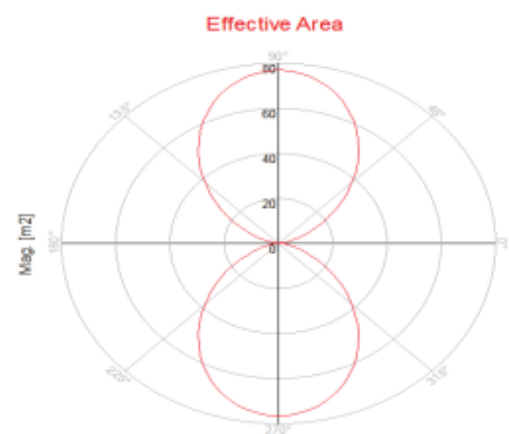

Phi (0.000 to 360.000)

Figure 6: 2D radiation pattern of the proposed antenna.

\section{Experimental Setup}

- Prototype antenna fabricated on $1.6 \mathrm{~mm}$ thick FR4 substrate.

- Copper layer thickness was $17 \mu \mathrm{m}$.

- Agilent 4395A network analyser was used for a frequency sweep of $0-500 \mathrm{MHz}$.

- Experiment was carried out in room conditions.

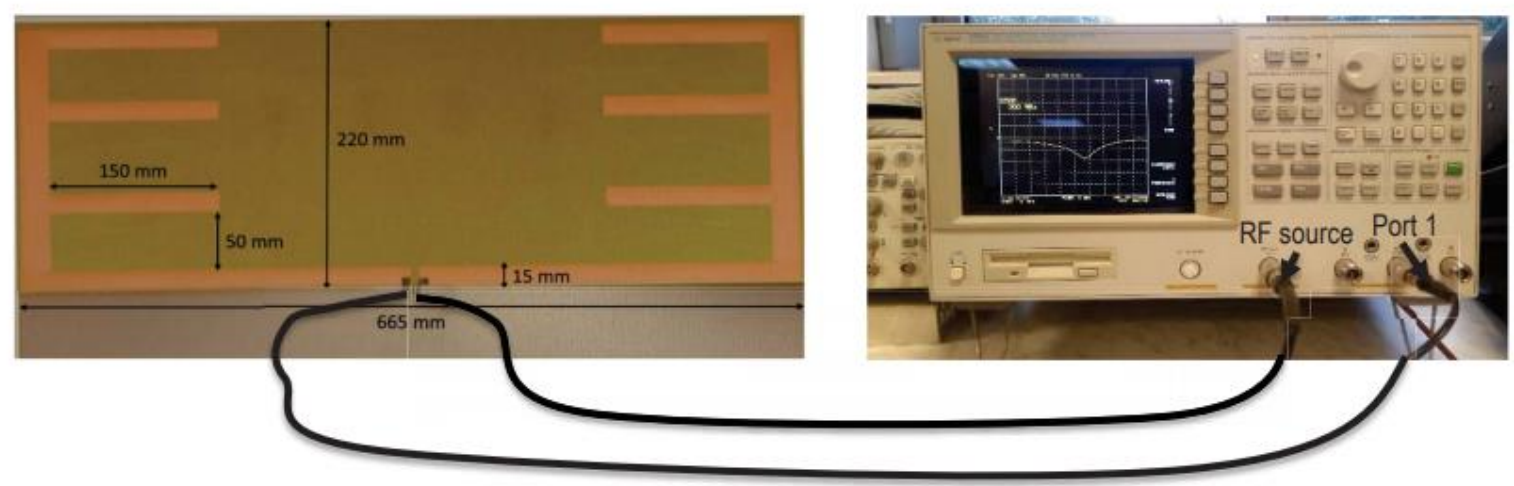

Figure 7: Prototype antenna and experimental setup block diagram.

\section{Results}

- Antenna centre frequency is $104 \mathrm{MHz}$.

- Bandwidth is $8 \mathrm{MHz}$ for VSWR $\leq 2$.
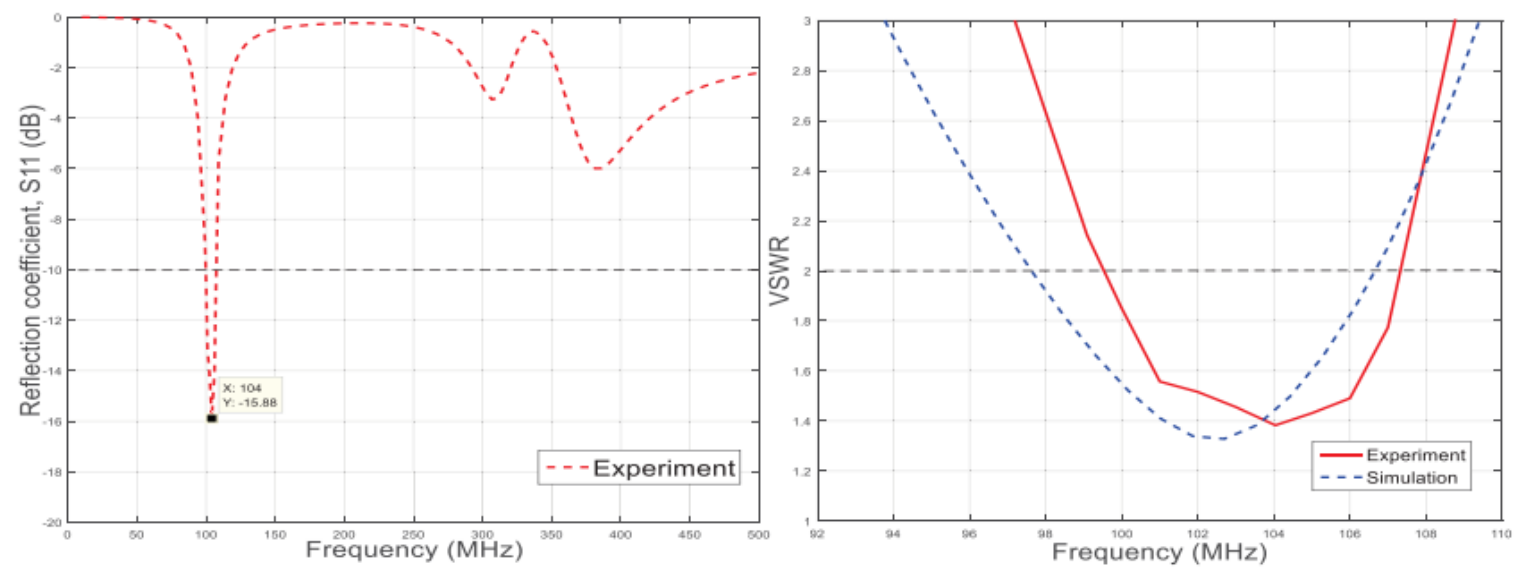
Figure 8: S11 and VSWR characteristic comparison of measured and simulated values.

\section{Conclusions}

Adding extra radiating arms on a dipole antenna can significantly reduce antenna size.

Laboratory prototype antenna achieved a $55 \%$ reduction in length compared to a conventional dipole of $100 \mathrm{MHz}$.

The antenna delivers typical dipole radiation pattern delivers with directivity gain of $2.06 \mathrm{dBi}$.

Proposed antenna shows significant improvement compared to [5], [6].

\section{References}

1. K. Takahashi, J. Igel, H. Preetz and S. Kuroda, "Basics and Application of Ground-Penetrating Radar as a Tool for Monitoring Irrigation Process," in Problems, Perspectives and Challenges of Agricultural Water Management, InTech, 2012, p. 160.

2. D. G. Smith and H. M. Jol, "Ground Penetrating Radar: Antenna Frequencies and Maximum Probable Depths of Penetration in Quaternary Sediments," Journal of Applied Geophysics, vol. 33, pp. 93- 100, 1995.

3. M. Nagatoshi, H. Morishita and S. Tanaka, "A Study on an Improvement of Folded Bow-Tie Antenna by Adding Additional Elements," in IEEE International Symposium on Antennas and Propagation (APSURSI), Washington, 2011.

4. J. Kim, M. Nagatoshi and H. Morishita, "Study on Miniaturization of A Strip Folded Dipole Antenna with Two Linear Conductors," in European Conference on Antennas and Propagation (EUCAP), Rome, 2001.

5. P. Patel, K. Dwibedi, R. Poonkhuzhali and D. Thiripurasundari, "Miniaturized Dipole Antenna using Koch Fractal Technique for Wearable Application," in International Conference on Communication and Signal Processing, Melmaruvathur, 2013.

6. M. Nagatoshi, S. Tanaka, S. Horiuchi and H. Morishita, "A Study on Wider Bandwidth of BowTie Antenna with Folded Elements," in IEEE Antennas and Propagation Society International Symposium (APSURSI), Toronto, 2010. 